\title{
Medicinal Leech Dosage Form
}

National Cancer Institute

\section{Source}

National Cancer Institute. Medicinal Leech Dosage Form. NCI Thesaurus. Code C161767.

Whole, live, medicinal leech, usually of the Hirudo genus (e.g. Hirudo medicinalis, Hirudo verbana), usually intended to be applied to the skin in order to restore or improve local blood flow or to provide other local effects. After attaching itself to the host, the leech creates an incision in the skin and secretes saliva containing a variety of active substances (e.g. anaesthetics, anticoagulants, anti-inflammatories, vasodilators) that allow it to feed on the blood of the host. 